\title{
A tarefa artística do ato de conhecer: estética, criação e reexistência em Paulo Freire
}

\section{The artistic task of the act of knowing: aesthetics, creation and reexistence in Paulo Freire}

\section{La tarea artística del acto de conocer: estética, creación y reexistencia en Paulo Freire}

\author{
Aristóteles de Paula Berino ${ }^{1}$ \\ Luciana Dilascio Neves ${ }^{1}$ \\ Vanessa de Andrade Lira dos Santos ${ }^{1}$
}

DOI: http://dx.doi.org/10.20435/serie-estudos.v26i58.1600

\begin{abstract}
Resumo: Citada em várias passagens da obra de Paulo Freire, a questão estética ou artística está dimensionada como parte fundamental das formulações prático-teóricas da pedagogia freireana. Este trabalho constitui-se a partir de um diálogo a respeito da problematização desta questão estética no pensar de Freire, refletindo as questões implicadas nesta compreensão, assim como a relação que a criação constitui junto à política, à medida que se torna emergente, também em nosso próprio momento político, a necessidade de inventar modos e estratégias pedagógicas a partir da contínua conscientização das questões políticas e socioculturais que nos atingem. As abordagens desenvolvidas sobre o tema em questão constituem como ponto de interseção à íntima relação entre arte, política e educação, e a compreensão da força da dimensão criadora como abertura de possibilidades no campo educacional e das reexistências; como contraponto à política mercadológica do determinismo histórico temporal dos poderes dominantes. Compreende-se que há muito ainda que aprofundar a respeito da questão estética em Paulo Freire, contribuindo com a emergência de novas práticas de luta e criação.
\end{abstract}

Palavras-chave: Paulo Freire; criação; reexistência.

Abstract: Repeatedly cited in several passages in Paulo Freire's work, the aesthetic or artistic question is dimensioned as a fundamental part of the practical-theoretical formulations of Freire's pedagogy. This work is based on a dialogue about the problematization of this aesthetic issue in Freire's thinking, reflecting the issues involved in this understanding, as well as the relationship that creation constitutes with politics, as it becomes emerging, as well, in our own political moment, the need to invent pedagogical ways and strategies based on the continuous awareness of political and sociocultural issues that affect us. The approaches developed on the subject in question constitute a point of intersection with the intimate relationship between art, politics,

\footnotetext{
${ }^{1}$ Universidade Federal Rural do Rio de Janeiro (UFRRJ), Seropédica, Rio de Janeiro, Brasil.
} 
and education, and the understanding of the strength of the creative dimension as an opening of possibilities in the educational field and of reexistences; as a counterpoint to the market policy of the historical temporal determinism of the dominant powers. It is understood that there is still a lot to go into about the aesthetic issue in Paulo Freire, contributing to the emergence of new practices of struggle and creation.

Keywords: Paulo Freire; creation; reexistence.

Resumen: Citada en varios pasajes de la obra de Paulo Freire, la cuestión estética o artística se dimensiona como parte fundamental de las formulaciones práctico-teóricas de la pedagogía de Freire. Este trabajo parte de un diálogo sobre la problematización de esta cuestión estética en el pensamiento de Freire, reflejando las cuestiones envueltas en esta comprensión, así como la relación que constituye la creación con la política, a la medida que se vuelve emergente, en nuestro propio momento político, la necesidad de inventar formas y estrategias pedagógicas basadas en la conciencia continua de las cuestiones políticas y socioculturales que nos afectan. Los enfoques desarrollados sobre el tema en cuestión constituyen un punto de intersección con la íntima relación entre arte, política y educación, y la comprensión de fuerza de la dimensión creativa como apertura de posibilidades en el campo educativo y de las reexistencias; como contrapunto a la política de mercado del determinismo histórico temporal de los poderes dominantes. Comprender que aún queda mucho por profundizar sobre el tema estético en Paulo Freire es un modo de contribuir al surgimiento de nuevas prácticas de lucha y creación.

Palabras clave: Paulo Freire; creación; reexistencia.

\section{INTRODUÇÃO}

Este trabalho parte de um diálogo entre os seus autores, que traz como questão fazer pensar - a partir de extratos presentes em obras de Paulo Freire, os quais o educador referia-se à questão da estética como parte integrante de sua concepção educativa -, qual o sentido e as imbricações da dimensão estética em sua formulação conceptiva de educação. Quais eram as relações entre estética e política na sua pedagogia da libertação? E em que sentido tal compreensão poderia contribuir para o pensar e a prática pedagógica próprios ao nosso atual momento histórico-político?

Se termos tais como "artístico", "artista", "estética" aparecem em inúmeras passagens de seus escritos, em quase sua maioria estão se referindo não às atividades ou modalidades artísticas em específico, mas à qualidade inerente à arte ou à estética enquanto processo de criação, processo de elaboração, processo que se faz fazendo, construção; para apresentarmos algumas repercussões semânticas que tais termos podem fazer corresponder em sua formulação pedagógica.

No seu diálogo com Paulo Freire (FREIRE; SHOR, 2021, p. 167), Shor remete à ideia freireana de que "[...] o professor é um artista e um político", e, argumentando 
que "[...] o que tem sido mais evidente é a política da pedagogia - como uma atividade social em favor da liberdade e contra a dominação [...]", procura discutir, indagando ao próprio Freire: "[...] de que modo o professor é um artista [...]"? Nessas e em outras passagens, estarão presentes as concepções do educador a respeito desta questão, mas, para além de procurarmos desenvolver reflexões em torno da dimensão estética em Paulo Freire, conforme nossas interpretações, tentamos refletir sobre a atualidade desta compreensão, principalmente em relação ao político e à extrema emergência que nos impõe, tanto a respeito da necessidade de apreensão e compreensão dos problemas que nos são inerentes como da invenção de estratégias e pedagogias que nos permitam buscar outras possibilidades para o nosso próprio momento político.

A questão estética em Freire abre inúmeras possibilidades de reflexão, muito além das que procuramos aqui contribuir. Não apresentamos exemplos de metodologias, mas buscamos, a partir de uma compreensão que, conforme acreditamos, encontra-se na raiz das concepções freireanas, fazer refletir a necessidade indicotomizável de conscientizações e compreensões dos problemas particulares do próprio tempo histórico e a predisposição para a invenção de estratégias que, elaboradas em correspondência com tais problematizações, propiciem escapar da dominação, em prol de uma educação para liberdade. Nisto, existirão nas estratégias um esforço em se fazer ver e descobrir o que há para ver, em se fazer pensar e descobrir o que há para se pensar, o que há para se fazer, sentir, imaginar. Neste sentido freireano, nenhuma problematização política poderá estar mais indissociável de uma dimensão criadora.

As reflexões sobre a questão da estética em Freire estão divididas neste trabalho em duas seções. Cada uma apresenta um determinado olhar e abordagem sobre tal questão. Contudo, em ambas aparecem os pontos de interseção em que se encontram o cerne das concepções freireanas, e que aqui nos interessa, a saber: a dimensão criadora como força contra o determinismo histórico temporal dos poderes dominantes, especificamente demarcado, desde os tempos de Freire até os atuais, pelo neoliberalismo. A primeira seção incide nas questões sobre as tensões e os conflitos entre a dimensão estética e uma educação projetada para o produtivismo e o resultado mercadológico, com a necessidade que nos cumpre o resgate da dimensão estética na formação educadora. A segunda seção tem certo tom de manifesto, ao incidir sobre o aspecto de denúncia ao determinismo 
neoliberal que é imanente às concepções freireanas, e cuja "necessidade de conscientização" e de sua "atualização" (FREIRE, 1996, p. 54) é defendida até as suas últimas publicações. Em ambas as seções, seja considerando as questões políticas no âmbito educacional formal ou as questões político-pedagógicas que envolvem todo um corpo sociocultural, encontra-se a vinculação da luta e dos processos de criação para fazer ler o mundo, fazer ver, imaginar, sentir, pensar o que se encontra por vir, ainda não apreendido, não elaborado, não inventado... no delimitado campo das ideologias dominantes.

Neste diálogo com Freire, procuramos, assim, correlacionar também com algumas questões e autores vinculados ao nosso próprio momento histórico-político.

\section{EDUCAÇÃO COMO EXERCÍCIO ESTÉTICO}

O título do texto de Rubem Alves, que inicia um importante trabalho de Duarte Junior (DUARTE JR., 1981), traz em si o cerne dos conflitos implicados em se pensar estética e educação entrelaçadas em um projeto, seja pensando de dentro ou de fora das escolas brasileiras. O desafio está posto: "A utilidade e o prazer, um conflito educacional" (ALVES, 1981, p. 9). São tantas as nuances presentes nas reflexões a partir deste título que nos é demandado um esforço de entendimento, na tentativa de ao menos pincelar o dilema exposto. Antes mesmo de adentrar no texto em si, já somos levados a pensar na relação utilidade e prazer, e seus desdobramentos no campo da educação. Pensemos aqui em um espaço ainda mais recortado, o campo dos saberes e fazeres que regem as aprendizagens no mundo. "Servir para" sempre foi um pressuposto para grande parte de nossas ações no mundo do trabalho, e, consequentemente, no contexto educacional, já que este trata, em seu sentido técnico, dos modos de preparar os sujeitos para o exercício de ser um cidadão inserido socialmente. Chegamos aqui no ponto que gera a colisão "utilidade e prazer", e em um campo com desdobramentos mais agudos, estética e educação. Conciliar essas dimensões pode parecer algo absurdo, se tivermos como referência os meios de produção capitalista, que regem as nossas relações de trabalho e, como consequência, interferem diretamente nas condições de se pensar educação na contemporaneidade.

Nesta perspectiva, o conflito entre utilidade e prazer, recortando aqui o campo educacional, é regido por um entendimento unilateral de ser sujeito no mundo, contextualizado fortemente pela produtividade. O que os sujeitos "produzem" ao 
se reconhecerem estéticos? E quais as reverberações destes sujeitos ao se reconhecerem como agentes estéticos nas redes que produzem em suas relações? 0 utilitário pode ter características estéticas enquanto objeto palpável, que se coloca no contexto das negociações implicadas em valores capitais. Pode também gerar sensações de prazer, ao ocupar lugares de satisfação física e emocional na vida das pessoas. No entanto, a estética não é tomada, nesta relação mercadológica, como condição própria de ser gente, como parte inseparável dos processos que compõem o próprio sujeito no mundo, descolada de qualquer princípio econômico.

Rubem Alves (1981, p. 9) aponta, logo no início de seu texto sobre utilidade e prazer, a zona crítica que rege esta discussão: "E aqui está alguém que sugere que a educação seja pensada a partir da beleza". E logo a seguir coloca campos díspares em uma disputa impensável: "o poeta e o músico são mais importantes que o banqueiro e o fabricante de armas, o que sem dúvida provocará sorrisos tanto nos vencedores quanto nos vencidos" (ALVES, 1981, p. 9). E ao tratar dos "sorrisos" provocados, logo após citar uma comparação no mínimo curiosa, recoloca o estético como elemento conclusivo da disputa, exatamente uma ação realizada aqui no polo do prazer e da ironia. Dentro de sua afirmação desconcertante, está o borbulhar que se choca com o ordenamento próprio de um posicionamento utilitário diante dos objetos do mundo. E mais à frente, ao afirmar que "[...] a alienação estética produz sonos mais confortantes..." (ALVES, 1981, p. 10), recoloca-nos novamente na experiência dos sorrisos provocados anteriormente, que são gerados pelo deslocamento de sentidos, que impede o sono dos sujeitos determinados por uma lógica posta.

A lógica da sociedade industrial, como aponta Rubem Alves (1981, p. 10), "[...] fez conosco o que um esquartejador faz com um corpo: desmembrou-nos, desmontou-nos numa série de funções independentes e frequentemente contraditórias". E, se pensarmos em funções estéticas como um elemento encaixado nestes fragmentos, elas até podem ser minimamente aceitas. E sugadas produtivamente pela máquina que demanda retorno, resultado.

O problema surge no modo como uma educação emancipadora se apropria da perspectiva estética. Na verdade, usar a expressão "se apropria" já é uma traição que a dificuldade de nomear nos prega. Não se trata de apropriação, mas da dimensão estética como parte integrante do sentido próprio de educação. "Educação como atividade estética" (ALVES, 1981, p. 10) estaria para a vida como 
o brinquedo para o lúdico. Uma educação que se volta para si mesma como ato criador e retorna para a vida, nas idas e vindas das pessoas entre si e com o mundo, desenvolvendo o que não se precifica. Cabe ressaltar neste ponto de nossa reflexão que não estamos caminhando para um entendimento romantizado da relação educação e estética. Nosso intuito é analisar o campo estético como uma dimensão fundante da educação, que religa as várias camadas de ser humano.

Para dialogar com Paulo Freire, partimos da relação entre expressões e palavras, utilizadas por ele para pensar a formação como um ato estético. Coletamos aqui um desses pedaços, que nos faz pensar os sentidos de formar e de criar: o "processo de formação" como "[...] necessariamente um processo artístico" (FREIRE; SHOR, 2021, p. 201). Ao compreender formação como necessariamente um processo artístico, Freire traz para nossa análise a palavra "modelagem", e sua relação com o que ele chama de "novo nascimento", como potencial fazedor que pode convergir como potencial formador, movimento dialético entre o fazer e o pensar sobre o fazer. Para além de resistir, o homem tem potência para inventar.

Fayga Ostrower (2001), assim como Paulo Freire, entende o homem em sua plenitude ao se fazer formador, para além das suas habilidades de ser fazedor de coisas. Por analisar a criatividade e os processos de criação, compreende a forma em suas múltiplas significações. Ao imprimir força em uma certa matéria, modulando a energia despendida entre vigorosa e suave, ao mesmo tempo em que pensa e cria as imagens mentais que deseja desvelar no suporte de que se apropria, o sujeito produz formas. Plasma ideias em matéria, apropria-se de recursos para gestar formas. Este é um entendimento simplificado e plástico de formar. Dito isso, fazedor e formador se fundem em apenas um ato, como quem pensa e forma no próprio ato de pensar, o que implica relações que não se estabelecem em uma zona neutra ou estanque.

Freire fala do educador como ser formador, e entendemos de maneira ampliada a natureza educativa de sua concepção, pois não se forma a si nem ao outro descolado das relações, as mais amplas e complexas possíveis. "Estabelecer relacionamentos entre os múltiplos eventos que ocorrem ao redor e dentro dele" (OSTROWER, 2001, p. 9) é pressuposto para o que Paulo Freire considera como "jogo estético" no campo da formação. É "[...] a capacidade de, intervindo no mundo, conhecer o mundo" (FREIRE, 1996, p. 15) que torna o homem para além de ser fazedor, que o faz formador. Trazemos para a nossa reflexão o estabele- 
cimento de relacionamentos entre os múltiplos eventos, que se desenrolam na própria vida, e a capacidade de conhecer o mundo ao intervir nele. Essas ações dependem de determinantes que se encontram dentro e fora do homem: o homem que toma consciência dos múltiplos eventos que acontecem fora dele, e das variadas formas de entendê-los, partindo assim para as relações possíveis entre esses eventos entre si e entre as suas demandas internas, já que, ao afetar, afeta; e, ao ser afetado, retoma as manobras que o fazem um ser formador. Ele conhece enquanto intervém na realidade e precisa necessariamente refazer caminhos, já que tornou, em sua própria elaboração, o mundo uma outra coisa.

Retomamos aqui a ideia das relações possíveis diante do e imerso no que ocorre "ao redor e dentro dele" (OSTROWER, 2001, p. 9), pensando nas manobras que tornam o homem formador. Façamos para isso uma analogia com formas diferentes de olhar: primeiro, um olhar gratuito de dentro; depois, um olhar "neutro" de fora; adiante, um olhar crítico de dentro; por fim, um olhar participativo de fora. Apenas estando dentro, sem pensar este lugar, o homem vaga no fluxo natural deste espaço, recebe os estímulos dele, sente dores ou se agita nele, responde aos afetos gerados pelos eventos. Ele olha, porque a luz reflete nos objetos e retorna à sua retina, e sente os efeitos desses raios que invadem sua percepção. Exercita aí um fragmento de sua humanidade. Pensemos então em um olhar "neutro" de fora: este só pode acontecer neste campo hipotético que criamos agora, já que essa limpeza não residiria neste movimento, pois o descolamento implicaria sempre fragmentos residuais deste deslocamento. Mas, se isso fosse possível, o homem olharia, lá do alto ou a distância, para uma massa disforme de coisas, pois não teria dentro de si ferramentas para decodificar as formas a que não teve um acesso anterior. A neutralidade acontece apenas como ficção, ou como manipulação de uma determinada realidade. No passo seguinte de nossa empreitada imaginativa, teremos um problema de execução de nossa análise, pois tocaremos na radicalidade de não poder determinar um movimento sem implicar dentro dele mesmo o outro. Aqui reside o movimento que nos retira de um eixo confortável, em que cada coisa parece ocupar o seu lugar. Teremos de imaginar o homem que, ao lançar um olhar participativo de fora, torna crítico seu olhar de dentro e, ao mesmo tempo, participa de fora por ser presença do e no que olha. Temos uma relação que expressa interdependência fora do prumo de sucessivos determinados, já que nem sempre ocorrem um após o outro no tempo e no espaço. Estamos diante do estático e do 
dinâmico, que não podem ser apreendidos definitivamente ou isoladamente ao se elaborar do mundo. Retomando o pensamento, que gerou nossa analogia sobre o olhar: o homem conhece enquanto intervém na realidade, e em sua manobra elabora um mundo novo, que demandará novas manobras neste duplo e uno que se situa ao redor e dentro.

Percebemos até aqui que, entre o entendimento de fazer e de criar, ações inerentes à nossa condição humana, existem nuances que multiplicam as formas de cambiar entre as forças internas e a codificação das manifestações que se dão na vida de toda gente. Essas forças, que Schiller (2002) classifica como impulsos, são capazes de gerar ampliação ou atrito ao se perceber o próprio mundo. Tomaremos de empréstimo as palavras do próprio Schiller (2002, p. 70) para pensar esta questão: "[...] se a força do pensamento se antecipa à sensibilidade e a pessoa substitui o mundo, ela deixa de ser força e sujeito autônomos na mesma proporção em que toma o lugar do objeto". Os dois movimentos que aparecem como "pontos cegos" na alegoria que desenrolamos mais acima, para pensar nos lugares de onde o homem supostamente olharia ao inventar o mundo, servem-nos de certa forma para ampliar o entendimento sobre ser fazedor e ser formador. A força que "se antecipa", na hipótese de Schiller, é a do pensamento, que ele chamaria de impulso formal. Se ela, em sua ânsia determinante, atropela os afetos, vira imediatamente e exatamente o que não quer, objetifica-se. Ao tentar desfazer um outro impulso, o pensamento se retira de seu próprio lugar e se reduz, ou perde potência. A engrenagem de se modificar e perdurar funciona a partir de forças díspares e, ao mesmo tempo, complementares. "Se o homem é apenas forma, não tem nenhuma forma" (SCHILLER, 2002, p. 70).

Pensemos aqui hipoteticamente em pessoas "diluídas" no mundo, como um estar dentro como apenas replicador de coisas. Indiscutivelmente, ele pode se apoderar tecnicamente de instrumentos e ferramentas que o permitem ser produtivo neste lugar, e pode repetir o seu fazer de incontáveis maneiras. Mas não pode formar em toda sua potência enquanto somente submerso, ou, nas palavras de Schiller (2002, p. 37): “[...] eternamente acorrentado a um pequeno fragmento do todo, o homem só pode formar-se enquanto fragmento do todo, ouvindo eternamente o mesmo ruído monótono da roda que ele aciona". O homem é regulado pela "[...] acomodação a este hoje normalizado" (FREIRE, 2019, p. 115), perdendo a nitidez de seu olhar, tendo um foco aproximado e fixado neste 
pequeno fragmento de mundo. Como uma experimentação simplista, é possível imaginar esta perspectiva: ao se fixar em frente e bem próximo a um objeto, que nunca foi pensando a partir de qualquer outra posição, o nosso olhar sofre um grau de embaçamento que impede uma ampliação do campo de visão. E se esse olhar não se desloca, não vagueia por outras fontes perceptivas, se permanece firmado neste mesmo objeto, este passa a ser a sua única realidade possível, ele ocupa o lugar de qualquer variável possível do campo.

Freire (1996) trata deste homem estético, "corpo consciente criador de beleza”, como ser capaz de promover um encontro solidário entre mãos e mentes. Parece que a virtude desta perspectiva estética humana está na relação entre dignidade e felicidade. Desta forma, a beleza tratada aqui implica claramente na renúncia de um posicionamento ensimesmado no mundo (que, sem considerar o outro, segundo as próprias palavras de Freire, ainda está no campo do suporte). Estaríamos tratando de um campo em que a felicidade só pode ser una se for também partilhada, assim, o corpo capaz de criar beleza só o é porque está diretamente ligado a outros corpos e mentes, num projeto coletivo de mundo.

Ao compreender o ser humano como criador de beleza, na medida em que promove este encontro solidário com o mundo, Freire não romantiza a presença humana nem a partilha dos espaços onde se relaciona com os outros. Ao contrário, ele reconhece a necessidade de uma experiência total e nomeia as implicações incluídas nas práticas de aprender e ensinar na relação com os outros e com o mundo, como "[...] uma experiência total, diretiva, política, ideológica, gnosiológica, pedagógica, estética e ética..." (FREIRE, 1996, p. 13).

\section{ARTE E POLÍTICA EM PAULO FREIRE: REINVENTAR PEDAGOGIAS E ESTRATÉGIAS DA LUTA}

Na live Paulo Freire: o menino que lia o mundo, Carlos Rodrigues Brandão ${ }^{2}$ recua à Grécia antiga para estabelecer um paralelo entre a concepção de Paideia ${ }^{3}$ e a educação freireana. Segundo Brandão, Paideia constitui o primeiro sentido

\footnotetext{
2 Paulo Freire: O menino que lia o mundo. Uma conversa entre Ana Mae Barbosa e Carlos Rodrigues Brandão. Mediação de Renata Bittencourt. Transmitida pelo Instituto de Arte Tear, em 13 de julho de 2021. Disponível em: https://www.youtube.com/watch?v=Q7_2Y6eGyZA. Acesso em: 2 set. 2021.

${ }^{3}$ Para o sentido de Paideia, Brandão menciona e tem como referência o livro Paideia. A Formação do Homem Grego, de Werner W. Jaeger.
} 
de cultura na Grécia, demonstrando que as primeiras formas de pedagogia grega ocorreram através da poesia. Estabelecendo aproximações com o que acontece em sociedades tribais, comunidades quilombolas, camponesas e outras, nesta Grécia, antes das formas institucionalizadas da educação, era a partir da poesia, dos cantos, mitos e outras formas de criação que se constituía o sentido de formação ou de educação, ajudando ao grego tecer, pensar e elaborar quem se é, sua relação com o mundo, seus dramas, cosmovisões. Mas o que Brandão busca fazer correlacionar é que nestas culturas não estão separados os atos de criação e de educação. Brandão menciona, ainda, ter sido lembrado por Foucault de que o ideal da cultura grega era criar na pessoa que se educa a obra de arte de si mesmo. E é esta concepção de educar-se para criar-se e recriar-se a si mesmo, e assim ao mundo, que Brandão considera relacionada à pedagogia freireana.

Retornando aos diálogos entre Ira Shor e Paulo Freire citados na introdução, pelo qual "[...] o professor é um artista e um político", e a pergunta de Shor a Freire a respeito "[...] de que modo o professor é um artista [...]"? (FREIRE; SHOR, 2021, p. 167), reelaboramos esta pergunta para desenvolver a reflexão em nosso próprio contexto atual: como pensar hoje a ação artística em conjunção com a questão de um devir político em que seja possível ensejar e sonhar transformações necessárias e desejadas?

Aproximando um pouco mais tal indagação do nosso contexto e realidade atuais, formulamos a pergunta ainda de um outro modo: considerando a brutal objetividade racionalista, em que questões políticas são conduzidas em prol das garantias econômicas de grupos de poder dominantes, com consequências violentas e degenerativas em âmbito social, cultural, político e econômico para maior parte dos contingentes populacionais, como pode a arte, dicotomizada da objetividade das relações em que este mundo se movimenta, relegada ao puro subjetivismo e/ou exilada à condição de utopia como modo impotente de realização, ou, ainda, apropriada pelos circuitos dominantes, exercer de fato uma ação na esfera política? Não colocamos em questão que a arte exercerá seus efeitos em âmbitos individuais, mas indagamos se, e de que modo, pode a arte exercer uma ação na instância política e coletiva desta atual condição do mundo, em sua ação racionalista e orquestrada para a determinação. Ou seja, pode a arte exercer alguma transformação nas relações que marcam as determinações políticas impulsionadas pelos dominadores? Para além do âmbito das transformações in- 
dividuais, pode a arte cooperar para uma transformação política, social e cultural coletiva mais ampla, considerando que, para Freire, a própria ideia de criação de si próprio não está separada da proposição de recriação também do mundo?

Nossa proposta é pensar essas perguntas dialogando com Paulo Freire, sem deixar de salientar a parcialidade das reflexões estabelecidas, consideradas a partir de nosso próprio posicionamento. Mas conscientizar-se a respeito desta relatividade do pensar corresponde, a nosso ver, às concepções freireanas, na compreensão do permanente movimento de busca e do ato de conceber que se projeta em devir e que se realiza pelas diferenças entre modos de pensar e imaginar, e pelo diálogo. Refaz sua proposta do contínuo movimento de criação e recriação de si mesmo e do mundo, pela dialética.

Há duas considerações totalmente interacionadas que aparecem na obra Pedagogia da Autonomia, e pelas quais iniciamos a construção desse diálogo com o pensar de Freire. São elas: a consciência do inacabamento e o reconhecimento de que somos "[...] condicionados, [mas] não determinados" (FREIRE, 1996, p. 19, grifo nosso). Tais considerações "[...] inscrevem o ser consciente de sua inconclusão num permanente movimento de busca" (FREIRE, 1996, p. 57). "Inacabado e consciente do inacabamento [...] o ser humano se faria [...] um ser de opção, de decisão" (FREIRE, 1996, p. 110), e uma pedagogia da autonomia se voltaria para as experiências da liberdade, para "[...] experiências estimuladoras da decisão e da responsabilidade" (FREIRE, 1996, p. 107), pois não há, em Freire, dicotomia entre responsabilidade e liberdade. Pertence à liberdade a responsabilidade pelos riscos assumidos, no direito que "[...] tem a liberdade de decidir, mesmo correndo o risco de não acertar" (FREIRE, 1996, p. 106). Mas a consciência do inacabamento projeta também a própria liberdade neste movimento em devir, de maneira que o fundamental não está nos fins, como resultado, mas no próprio processo. Processo que, em cada um, vai metamorfoseando-se em desenho próprio, não um desenho sempre em linha reta e ascendente tal como é a falsa linha projetada pelo positivismo neoliberal, direcionada sempre para o resultado, para a determinação; para dizer o que é e o que não é, para impor ao ser uma lógica abstrata e absoluta, que não é a dele.

Entendemos que este desenho próprio das concepções freireanas encontra-se intimamente relacionado com os processos na arte enquanto sentido de criação. É pela dinâmica da criação que tal desenho não existe a priori tal como 
mera representação ou como reconhecimento do já existente, mas enquanto forma e conteúdo indicotomizáveis que vão se construindo no processo com sua maneira particular de acontecer; é pela dinâmica da criação que o desenho não se constitui em significado unívoco e determinado (significado imposto arbitrariamente à forma, mas ausente dela mesma), mas se abre em trama de experiências, memórias, formas, significados plurais, cujos sentidos permanentemente precisarão ser reconstruídos na apreensão de cada um, e na dialética que incorpora os seres na coletividade. Assim é, para Freire, conforme acreditamos, a dinâmica do desenho no processo de vida dos sujeitos para criar-se a si mesmo, para a "construção" de sua própria "presença no mundo" (FREIRE, 1996, p. 53).

Seria neste âmbito, ao contrário do exílio em que é confinada a arte, condenada pela consciência neoliberal a viver à margem da "vida real"4 e dos destinos objetivos que realmente importam às conduções políticas do tempo histórico, que Paulo Freire compreendeu a importância fundamental da experiência criadora na vida dos sujeitos, não para fuga ou afastamento do real, mas sim para seu aprofundamento, para consciência crítica e em permanente reelaboração deste fato dado como real, que não existe como algo pronto e determinado. A despeito da dicotomia estrategicamente produzida entre arte e política, entre objetividade e subjetividade, entre razão e imaginação, entre forma e conteúdo, entre prática e teoria etc., Freire compreendeu a extrema necessidade de romper com estas falsas dicotomias como maneira de superação da farsa neoliberal com seu determinismo histórico.

Ao contrário da instrumentalização da linguagem que tem como função a transmissão, a alfabetização de adultos proposta por Freire é pensada enquanto maneira de reconstrução e reelaboração da linguagem e do pensar, como atos não dissociados. Se o mundo político focado na dominação e determinação do outro necessita da instrumentalização da linguagem para torná-la propícia à transmissão de suas narrativas e ideologias, é esta dinâmica própria à arte, à poesia etc., como elaboração e construção permanentes, antídoto contra o determinismo. Assim como os sujeitos, nos posicionamentos que assumem, em um dado momento teriam consciência de sua relatividade ou incompletude, as atividades de criação

\footnotetext{
${ }^{4}$ Afinal, até mesmo no âmbito educacional curricular, não é incomum vermos os alunos questionando qual o sentido que há em se estudar arte.
} 
também se aproximam de certa determinação - que as permitem constituir sua própria lógica - sem que se perca a consciência de sua relatividade. E como na criação a experiência do sentido precisa se complementar no outro, o círculo da determinação não se fecha e se abre num contínuo movimento de reelaboração. Neste ciclo, a experiência artística escapa das determinações e realiza-se como campo de possibilidades simultâneas. E é compreendendo esta dinâmica própria aos modos de criação que Freire (1996, p. 19) enseja escapar do círculo fechado das determinações políticas, para um "tempo de possibilidades".

É interessante observar que, para Freire (FREIRE; SHOR, 2021, p. 202), o ato de conhecer liga-se à "tarefa artística" que "tem qualidade de dar vida" e relaciona-se à experiência do desvelamento: "[...] conhecer é desvendar um objeto, o desvendamento dá 'vida' ao objeto, chama-o para a 'vida', e até mesmo Ihe confere uma nova 'vida'". Esta consideração ao ato de desvelar e "ler o mundo" correlaciona-se a algo fundamental, que é o de conferir sentido às coisas, às experiências e à própria existência. Desvelar e construir constituem-se na imbricada relação entre objetividade e subjetividade, na relação dos sujeitos no e com o mundo, pela qual o desvelamento do mundo dá corpo à presença dos sujeitos. A função da educação seria, assim, estimular e desafiar a produção não só da própria compreensão, como também a invenção da maneira pela qual se pensa, se faz, se cria, se vive. Seria, assim, "[...] o fundamental no aprendizado do conteúdo [...] a construção da responsabilidade da liberdade que se assume", na "[...] reinvenção do ser humano no aprendizado de sua autonomia" (FREIRE, 1996, p. 94).

Encontramos em Didi-Huberman (2015, p. 26) consideração relevante para se pensar uma função da arte na complexa relação com seu tempo histórico-político: em vez da conveniência passiva do "artista e seu tempo", propõe-se "o artista contra seu tempo". Justa proposição para se pensar uma atuação da arte diante dos poderes instituídos pela consciência histórica temporal. É esta função da arte como constante processo de elaboração em contraponto ao determinismo dos poderes hegemônicos que vemos latente na teoria-prática freireana e sua indissociável vinculação com a política.

Em função disto, faz parte desta íntima relação entre arte e política, em Freire, o processo de desvelamento da farsa constituída pelos poderes dominantes, assim como a assumida responsabilidade pelo processo de construção da própria existência pelos oprimidos. Há um inegável caráter de denúncia nas 
concepções freireanas, mas esta denúncia constitui-se como possibilidade contra o processo de naturalização das condições aberrantes da existência sob tutela dos dominadores, com a "[...] legitimidade da raiva contra a docilidade fatalista", contra esta ocultação da fonte geradora da tragédia, como meio de lutar contra "[...] a negação de mim mesmo" (FREIRE, 1996, p. 76).

Conforme Freire (1996, p. 100) percebeu - situação progressiva no nosso tempo - , "[...] é uma imoralidade [...] que se sobreponham, como se vem fazendo, aos interesses radicalmente humanos, os do mercado". A despeito da concretude material que constituem as situações da desigualdade, violência e opressão, ainda assim identifica-se a adesão dos oprimidos ao sistema de opressão, pela qual se torna claro "[...] que faz parte do poder ideológico dominante a vinculação nos dominados da responsabilidade por sua situação" (FREIRE, 1996, p. 83). Conforme entendemos, é possível dizer que Freire percebe, nas narrativas fatalistas neoliberais e nas instituições da sociedade civil que as consolidam, estratégias e técnicas de persuasão que visaram à introjeção da culpa e à conivência ao sistema.

Em muitos casos, a culpa pelo fracasso que sentem tais oprimidos do sistema neoliberal não é percebida em função da "[...] perversidade do sistema social, econômico e político em que vivem, e sim na sua incompetência" (FREIRE, 1996, p. 83). Se, por um lado, há justificativas mantidas no inconsciente, pelas quais a culpa explica-se pela autoimagem do despreparo, inadequação, pouca civilidade, fraqueza, entre outras, por outro lado, há narrativas motivadoras a respeito da docilidade do ser humano para aceitar a vida como ela é, como se os acontecimentos representassem sempre um processo natural, e não um processo que, em grande parte, faz parte das escolhas dos poderes dominantes. Como é também comum em nosso contexto atual, tais motivações incluem elogio à capacidade de adaptação e resignação, elogio ao trabalho, às pessoas íntegras e nacionalistas, com a promessa do merecimento religioso, entre outras formas persuasivas. De modo sucinto, seria desta maneira que, em vez da percepção do sistema opressivo, este passa a ser incorporado como salvação à condição existencial, pelo qual o sonho do oprimido é o de fazer-se imagem do opressor. Os que conseguem ascender aos modos de privilégio e status do sistema neoliberal tornam-se exemplos, de onde se perpetua a raiz religiosa do capital. Raiz mítica religiosa fatalmente marcada pela perpetuação das relações de dominação.

Compreendemos que, diferentemente do que corresponderia à solidarie- 
dade e à cooperação, há um fator psicológico que impulsiona inconscientemente a adesão aos mecanismos de perpetuação dos sistemas da injustiça e da violência. Neste sentido, Freire (1996, p. 83-4) menciona a necessidade de uma "psicanálise histórico-político-social" com a "extrojeção da culpa indevida", com "a 'expulsão' do opressor de 'dentro' do oprimido", que precisa ser "[...] substituída por sua autonomia e sua responsabilidade". Seria assim necessário "[...] desafiar os grupos populares para que percebam [...] a violência e a profunda injustiça que caracterizam sua situação concreta" (FREIRE, 1996., p. 80). Este desafiar não significa, no entanto, impor aos grupos uma forma de perceber, mas significa, no atuar pedagógico, estar juntos na prática dialética; construir juntos questões e soluções, a partir da criação de ações e estratégias que levem às investigações, aos desvelamentos dos e proximidades com os fatos e as razões relacionados às realidades que, desviados de sua devida atenção, tornam-se subjacentes, causas ocultadas, assim como também significa a possibilidade de encontrar, de descobrir, elaborar, novos modos de fazer, imaginar, relacionar-se, que favoreça sonhar "[...] com uma outra vida que vá além do imaginário permitido pelo poder" (BERINO, 2018, p. 337).

A legitimidade da raiva contra a farsa neoliberal significa, ainda, incidir um questionamento crítico a respeito das narrativas próprias a muitas das instituições de poder da sociedade civil - imbuídas das ideias de justiça, fraternidade, amor, liberdade, entre outros termos conceituais - e a cooperação que tais instituições mantêm com os avanços das perspectivas capitalistas e mercadológicas sobre as condições existenciais. No nosso entender, trata-se, como diria Freire (2019, p. 42), de uma falsa "[...] 'generosidade' que se nutre da morte, do desalento, da miséria". Naturalizam-se tais contradições no interior da sociedade civil, esses duplos que parecem permear quase todas as relações - quem usurpa é também quem oferece, quem oprime é salvador, reacionário é revolucionário etc. Mas não podemos deixar de produzir questionamento às naturalizações destes duplos no interior da sociedade civil. Por exemplo, a despeito da função que devem realizar, não conseguimos deixar de estranhar o fato de que instituições midiáticas-jornalísticas vinculadas à lógica neoliberal apresentem matérias diárias com tom de denúncia sobre a violência, o genocídio, as condições precárias na saúde, na educação, na vida das classes desfavorecidas etc., estando contudo aliadas à lógica da espoliação, do enriquecimento desmensurado de poucos, das imensas desigualdades e injustiças feitas em prol do favorecimento dos que 
detêm o poder. Além de mascarar a própria responsabilidade, essas denúncias não visam gerar a indignação ou a problematização da situação, mas angariar a credibilidade e a conivência através do sentimentalismo. Ao contrário da revolta, que é predisposição para a necessidade de recriação, o sentimentalismo tende para a acomodação, para a naturalização da situação apresentada. Como constata Freire (1996, p. 75) a conformação dirá: "É triste, mas, que fazer? A realidade é mesmo esta". Conforme Roberto Schwarz (2008, p. 29-30), "[...] a proximidade mistifica, estabelece um contínuo psicológico onde não há contínuo real". Ou seja, há um sentimentalismo inoperante que colabora como suporte emocional e psicológico, o qual conforta o mal-estar e isenta do compromisso e da responsabilidade pela existência do fato. Neste "contínuo psicológico", cria-se a acolhedora ideia de que todos nós somos vítimas de circunstâncias referidas sempre a algo além - este algo que, no capitalismo, reveste-se da impessoalidade dos processos naturais.

Mencionamos alguns aspectos relevantes que encontramos em Márcia Sá Cavalcante Schuback (2021) em relação ao nosso contexto político. Em concepção ensaística que tem como ponto de partida "a visão cinepoética" de Pier Paolo Pasolini, Schuback (2021, p. 9) entende acontecer, em nosso momento atual, uma versão contemporânea do fascismo, mutação do fascismo histórico. Esta concepção de um neofascismo já se apresentava nos ensaios de Pasolini na década de sessenta, estando relacionado a "[...] uma nova forma de capitalismo, estreitamente ligada às novas formas de tecnologia" (SCHUBACK, 2021, p. 29). Segundo Schuback (2021, p. 9), se as antigas formas de ideologias totalitárias tinham o propósito da exatidão e determinação de sentidos inequívocos, "[...] hoje a sua inequivocidade se exerce e se impõe por uma política da ambiguização", pelo qual a autora adota o termo "fascismo da ambiguidade". Para não nos alongarmos na complexa discussão em questão, sintetizamos que esta concepção de um fascismo da ambiguidade é também salientada na observação que Schuback faz de um poema de Pasolini escrito quando esteve no Brasil. Na "[...] sua cinepoética da cidade e dos corpos", ela observa que Pasolini teria flagrado "[...] o 'nó inextricável' da ambiguidade em que o fascista e o subversivo se confundem, em que quem tem os olhos arrancados pode virar logo quem arranca os olhos, em que se pode lutar tanto pelo fascismo quanto pela liberdade" (SCHUBACK, 2021, p. 36). Em nossa maneira de entender, esta constatação da imprecisão 
orientada pela ambiguidade, observada pela autora, permeia quase todos os fatos e acontecimentos hoje pelos quais o capitalismo neoliberal e financeiro é impensável "[...] sem as novas formas de tecnologia informacionais, da robótica, dos algoritmos, das redes sociais, do espetáculo midiático, da inteligência artificial [...] inteiramente nas mãos digitais de poderosas conglomerações inter, multi e transnacionais" (SCHUBACK, 2021, p. 40). Sua "[...] meta inequívoca [...] encontra, na ambiguização de todos os sentidos e valores, o seu método" (SCHUBACK, 2021 , p. 43). Sua arma, "[...] tornar todos os sentidos e valores equivalentes, cada coisa qualquer coisa, anulando as diferenças e exterminando, pela naturalização do ódio, o outro enquanto força de transformação e presença do possível no real devastado" (SCHUBACK, 2021, p. 127). Esta imprecisão pela qual toda afirmação pode conter a sua exata negativa, todas as "[...] expressões podem ser invertidas e pervertidas", "[...] todo sentido e valor podem ser virados contra si e contra qualquer outro" não é a ambiguidade da criação poética, não visa abrir-se em possibilidades, mas, estrategicamente, visa impedir movimentos de resistência, velar as instâncias de significações do real, confundir as possibilidades de ligação dos elos, para que a ação determinada pelo poder não encontre empecilhos. 0 que Schuback (SCHUBACK, 2021, p. 36) chama atenção na visão cinepoética de Pasolini, antevendo esta oscilação entre fascismo e subversão no corpo social e no imaginário brasileiro, é a extrema necessidade de se perceber a inoperância de nossas formas de resistências "e a urgência de reinventá-las".

E é nesta emergência da reinvenção de formas de resistência que entendemos a atualidade da conjunção arte-política na pedagogia como prática da liberdade em Paulo Freire. Seu atuar concentrou-se na criação de estratégias em que nossa rebeldia pudesse se tornar revolucionária. Como dizia, "[...] a rebeldia é ponto de partida indispensável, é deflagração da justa ira, mas não é suficiente" (FREIRE, 1996, p. 79). Para a transformação da realidade, é preciso que a postura rebelde se transforme em "revolucionária" (FREIRE, 1996, p. 79). A nosso ver, a revolução é uma ação que golpeia o determinismo do poder, mas, se como já alertava Walter Benjamin (1994, p. 128), o aparelho capitalista pode apropriar-se e propagar os temas revolucionários, "[...] sem colocar seriamente em risco sua própria existência e a existência das classes que o controlam", então é necessário pedagogias da estratégia, e a contínua invenção de pedagogias de resistências e de pedagogias da revolução pelas quais seja possível lutar contra o 
poder desse "capitalismo global tecnomidiático" em sua "[...] dinâmica de transformação constante [...] uma transformação que transforma tudo [...] menos o sentido da transformação. É a transformação que só consegue gerar um status quo, um dinâmico conformismo" (SCHUBACK, 2021, p. 53). Lembremos, assim, do pedido de Benjamin (SCHUBACK, 2021, p. 127) para que houvesse uma "refuncionalização" da arte, conceito tomado de Brecht, significando, a nosso ver, pensar hoje em como podemos reapropriar das mãos dos circuitos de poder capitalista o direcionamento do sentido de nossa produção, esquivando-se das tentativas nefastas do mercado de tudo apropriar-se, para esvaziar de sentido. E, como requisitou Paulo Freire, é preciso "unir para a libertação" (SCHUBACK, 2019, p. 234), inventando juntos modos e estratégias para uma pedagogia de nossa própria libertação. Uma política pedagógica que não se traduza em luta por um lugar privilegiado na imagem de mundo do opressor, mas que signifique "[...] nascer da superação da contradição" (FREIRE, 2019, p. 44); inventar outas formas de existir e reexistir em que sejam realmente viáveis possibilidades outras e múltiplas. Para Freire (FREIRE, 2019, p. 182), não há “[...] um tempo de diálogo e outro, diferente, de revolução [...] o diálogo é a 'essência' da ação revolucionária". Unir-se nas diferenças é a prática da "teoria dialógica" em contraponto com a tarefa que se impõe aos dominadores, "[...] a divisão dos oprimidos com que, mais facilmente se mantém a opressão" (FREIRE, 2019, p. 234). Significa, assim, superar sectarismos; unir-se nas diferenças contra a dominação do único.

No âmbito freireano, fazer política implica conscientizar-se das formas de fazer política, não só em relação àquela que claramente podemos identificar como política, mas também às que fazem parte de nossa maneira de fazer, de nos relacionar, de pensar, de imaginar, de nos posicionar etc. Implica com isso a invenção de pedagogias e estratégias para fazer pensar o próprio pensamento, para fazer ver o não visto, para fazer sonhar o sonhado e o não sonhado. Como menciona Schuback (2021, p. 127), resta-nos "[...] uma política dos sentidos, da precisão poética, da escuta e da voz [...]". Reencontrar e descobrir elos mesmo com as nuvens de fumaça produzidas. Compreender a íntima relação entre a luta e a criação.

Citando Amílcar Cabral, Freire (FREIRE; SHOR, 2021, p. 309) escreve: "Quão pobre é a revolução que não sonha". Bela reflexão em correspondência com a concepção freireana de "formação" e de "construção" em devir. E já não seremos 
nós a sonhar a revolução, mas a revolução que sonha em nós, para encontrar os sentidos da revolução no próprio processo revolucionário.

\section{CONCLUSÃO}

Em sua teoria-prática, Paulo Freire (1996, p. 22) constitui-se em exemplo de que, não só referente ao saber e às experiências, mas também aos modos e processos que nos levam a saber, experimentar, ver e fazer cumpre-nos criar as possibilidades para a sua produção ou a sua construção. Seu exemplo, entendido não como modelo, mas como possibilidade, refere-se à compreensão da tarefa que nele explicita-se, a luta que há na formação da realidade em devir. Assim, a característica que marca sua pedagogia é que o processo de criação-indissociável movimento tanto de "formação" de si mesmo como de "formação" coletiva, pela dialética - deve encontrar também na transformação da realidade a continuidade do movimento, a essência do que se move.

Nas abordagens desenvolvidas, são pontos de interseção a necessidade de se pensar a função educativa como embate às naturalizações, normatizações e ao esvaziamento das experiências e dos sentidos produzidos pelas condições mercadológicas e determinantes pelas quais as políticas dominantes são conduzidas. Em âmbito freireano, a educação resgata sua dimensão estética. Em contraponto à política da determinação, a educação convida aos deslocamentos, às leituras e desvelamentos do mundo, a descobrir as ligas entre instâncias da realidade e entre camadas do ser, aos partilhamentos das diferenças, ao reencontro do si consigo e do si no outro, neste tornar-se enfim movimento.

\section{REFERÊNCIAS}

ALVES, Rubem. A utilidade e o prazer: um conflito educacional. In: DUARTE JR., João-Francisco. Fundamentos estéticos da educação. São Paulo: Cortez/Autores Associados; Uberlândia, MG: Universidade de Uberlândia, 1981.

BENJAMIN, Walter. Magia e técnica, arte e política. Sérgio Paulo Rouanet. São Paulo: Brasiliense, 1994.

BERINO, Aristóteles. Para ser um ser no mundo: a humanização é uma poética em Paulo Freire. Revista Teias, Rio de Janeiro, v. 19, n. 55, p. 329-39, out./dez. 2018. 
DIDI-HUBERMAN, Georges. Diante do tempo: história da Arte e anacronismo das imagens. Vera Casa Nova. Belo Horizonte: Ed. UFMG, 2015.

DUARTE JR., João-Francisco. Fundamentos estéticos da educação. São Paulo: Cortez/Autores Associados; Uberlândia, MG: Universidade de Uberlândia, 1981.

FREIRE, Paulo. Pedagogia do oprimido. São Paulo: Paz e Terra, 2019.

FREIRE, Paulo. Pedagogia da autonomia: saberes necessários à prática educativa. São Paulo: Paz e Terra, 1996.

FREIRE, Paulo; SHOR, Ira. Medo e ousadia: o cotidiano do professor. 14. ed. São Paulo: Paz e Terra, 2021.

OSTROWER, Fayga. Criatividade e processos de criação. 19. ed. Petrópolis: Vozes, 2001.

SCHILLER, Friedrich. A educação estética do homem. Tradução de Roberto Schwarz Márcio Suzuki. São Paulo: Iluminuras, 2002.

SCHUBACK, Marcia Sá Cavalcante. O fascismo da ambiguidade: um ensaio conceitual. Rio de Janeiro: Ed. UFRJ, 2021.

SCHWARZ, Roberto. O pai de família e outros ensaios. São Paulo: Companhia das Letras, 2008.

\section{Sobre os autores:}

Aristóteles de Paula Berino: Doutor em Educação pela Universidade Federal Fluminense (UFF). Professor na Universidade Federal Rural do Rio de Janeiro (UFRRJ), no Departamento de Educação e Sociedade (DES/IM/Nova Iguaçu), e no Programa de Pós-Graduação em Educação, Contextos Contemporâneos e Demandas Populares (PPGEduc). E-mail: aristotelesberino@yahoo.com.br, Orcid: https://orcid.org/0000-0002-6013-7784

Luciana Dilascio Neves: Doutoranda do Programa de Pós-Graduação em Educação, Contextos Contemporâneos e Demandas Populares (PPGEduc) pela Universidade Federal Rural do Rio de Janeiro (UFRRJ). Mestre em Ciência da Arte pela Universidade Federal Fluminense (UFF). Professora do Departamento de Artes na (UFRRJ). E-mail: Idneves2014@gmail.com, Orcid: https://orcid.org/0000-0002-8095-5864 
Vanessa de Andrade Lira dos Santos: Doutoranda do Programa de Pós-Graduação em Educação, Contextos Contemporâneos e Demandas Populares (PPGEduc) pela Universidade Federal Rural do Rio de Janeiro (UFRRJ). Mestre em Educação, Cultura e Comunicação em Periferias Urbanas (UERJ). Professora de Artes Visuais nas redes FAETEC e SEEDUC/RJ. E-mail: vanessalirartes@gmail.com, Orcid: https://orcid.org/0000-0002-2683-8376

Recebido em: 10/09/2021

Aprovado em: 15/09/2021 
